\title{
Comparative evaluation of efficacy of hiora, terminalia chebula and chlorhexidine as mouth wash on dental plaque
}

\begin{abstract}
Introduction: Dental caries and periodontal diseases, the two arch criminals of oral cavity, are essentially caused by the micro-organisms present in dental plaque.
\end{abstract}

\begin{abstract}
Aim and objectives: Evaluate the relative effectiveness of Chlorhexidine, Hiora, and $T$. chebula mouth rinses on plaque reduction.

Materials and method: The present study was a randomized controlled crossover clinical trial. It was designed to evaluate and compare the efficacy of different mouth wash. Data obtained in relation to different assessing parameters at different phases of present study was subjected to statistical analysis using paired t- test.
\end{abstract}

Results: Chlorhexidine was more effective in reducing dental plaque compare to other mouthwashes.

Conclusion: Chlorhexidine shows better results compare to its herbal alternative but Hiora and Terminalia chebula mouthwash due to its natural ingredients has no reported side-effects and further studies with varied concentrations, different parameters and larger sample size are to be carried out to assess their efficacy of herbal mouthwash.

Keywords: dental plaque, chlorhexinde, hiora, Terminalia, chebula
Volume 8 Issue 4 - 2017

\author{
Rahul Gupta,' Om Prakash Yadav, ${ }^{2}$ Mohsin \\ Khan, ${ }^{3}$ Shubhi Kaushik, ${ }^{4}$ Naiem Ahmed, ${ }^{5}$ \\ Manju Panwar ${ }^{6}$ \\ 'Private Dental Practitioner, India \\ ${ }^{2}$ Research Scientist, Sardar Patel Medical College, India \\ ${ }^{3}$ Department of Public Health Dentistry, Tatyasaheb Kore Dental \\ College and Research Centre, India \\ ${ }^{4}$ Department of Prosthodontics, Crown and Bridge and \\ Implantology, Rajasthan Dental College and Hospital, India \\ ${ }^{5}$ Department of Oral and Maxillofacial Surgery, Rajasthan Dental \\ College and Hospital, India \\ ${ }^{6}$ Department of Public Health Dentistry, Rajasthan Dental \\ College and Hospital, India
}

Correspondence: Om Prakash Yadav, Research Scientist, Sardar Patel Medical College, A-44,Ashok Nagar, Purani Chungi, Ajmer Road, Jaipur, Rajasthan, India,

Email opyadav544@gmail.com

Received: October 03, 2017 | Published: October 10, 2017
Abbreviations: S. persica, Salvadora persica; T. chebula, Terminalia chebula; S. mutans, Streptococcus mutans; PII, plaque index.

\section{Introduction}

Dental caries and periodontal diseases, the two arch criminals of oral cavity, are essentially caused by the micro-organisms present in dental plaque. ${ }^{1}$ In India, nearly $60-65 \%$ of the child population is affected by dental caries and $10 \%$ has periodontitis., ${ }^{2,3}$ Dental plaque plays an important role in the development of dental caries and periodontal disease, which results in both dysfunction and loss of tooth. ${ }^{3}$ Mouthwashes are used to rinse the oral cavity for many reasons:

a. To remove or destroy bacteria.

b. To act as an astringent.

c. To deodorise.

d. To have a therapeutic effect by relieving infection or preventing dental caries. ${ }^{4}$

Hence these chemical methods of reducing plaque are appealing as they can provide significant benefits to patients who cannot maintain adequate mechanical plaque control. ${ }^{5}$ The digluconate of Chlorhexidine is a synthetic antimicrobial drug which is effective in vitro against both Gram-positive and Gram-negative bacteria and considered as gold standard. ${ }^{6}$. But it cannot be used on a long term basis because of various side effects like brown discoloration, taste perturbation, oral mucosal lesions, parotid swelling, enhanced supragingival plaque formation, gingival desquamation, and sometimes unacceptable taste. ${ }^{6}$ Hiora is an herbal mouthwash, has an active herbal ingredient: Meswak (Salvadora persica) which is a medicinal plant. It has been demonstrated that extracts of S. Persica improved gingival health and inhibited growth of cariogenic bacteria. ${ }^{7}$ A study reported that the mouth rinse with aqueous salvadora twigs extract causes significant reduction $(84 \%)$ in the adherence of bacterial cells (Streptococcus mutans) to buccal epithelial cells. ${ }^{8}$ In recent years, there has been focus on plants or plant products used in folk dental practice and one such herbal cocktail is Triphala, the herbal product of equal proportion of dry powder of Terminalia chebula, Terminalia belerica and Emblica officinalis. ${ }^{9}$ T. chebula suppress the growth of microbes, adherence of sugar and glucan induced aggregation of S. mutans. Mouth rinsing with a $10 \%$ solution of the extract inhibited microbial count. T. chebula demonstrated preventive action on dental caries has shown that owning to the microbial reduction may be attributed to the presence of tannins and flavonoid. ${ }^{10}$. An effective alternative to Chlorhexidine with all its good qualities and sans its unpleasant effects is highly desirable and has been long awaited. Literature review revealed very few in vivo studies worldwide assessing the effects of $T$. chebula extracts on dental plaque. Hence the present study was taken to evaluate the relative effectiveness of Chlorhexidine, Hiora, and $T$. chebula mouth rinses on dental plaque in 8-16year old children. 


\section{Materials and methods}

The present study was a randomized controlled crossover clinical trial. The study was designed to evaluate and compare the efficacy of Hiora, Terminalia chebula, and Chlorhexidine as mouth wash on dental plaque among 8-16 year old orphanage children of Jaipur city. Following ethical clearance from the concerned committee of the institute, written permission was obtained from the head of the orphanage which harboured around 150 children between the age group of 8 to 16years. On clinical examination and case history recording on the proforma, 72 children between the age group of 8 to $16 y$ ears were considered for present study based on the following inclusion \& exclusion criteria:

\section{Inclusion criteria}

a. Subjects with good general health.

b. Minimum of 12 gradable teeth.

c. Comparable socio-economic status.

\section{Exclusion criteria}

Subjects with relevant medical condition

\section{History of subjects with:}

1. Early onset periodontitis.
2. Acute necrotizing ulcerative gingivitis.

3. Gross oral pathology.

\section{Study material}

a. $\quad 0.2 \%$ Chlorhexidine mouth wash (Hexidine) $(500 \mathrm{ml})$

b. Hiora mouth wash (Himalaya) $(150 \mathrm{ml})$

c. $10 \%$ Terminalia chebula mouth wash

\section{Grouping of subjects}

Seventy two subjects considered for the present study into Group-1, Group-2 and Group-3 with 24 subjects in each group for use of three different mouthwashes during the three different phases of present cross over study. Modified Plaque index (PII) described by Loe H. ${ }^{11}$ was used for assessing dental plaque. On procuring the baseline recording of dental plaque of subjects, the orphanage custodians of 24 subjects of each group were handed over 24 tooth brush and a tooth paste tube of 180 grams each with the instruction that, hence forth under their supervision the subjects will be taking care of their oral hygiene making use of the tooth brush and tooth paste provided for the purpose till the end of the study. Different phases of the study were described by the schematic diagram (Figure 1). Data obtained in relation to different assessing parameters at different phases of present study was subjected to statistical analysis using paired t- test.

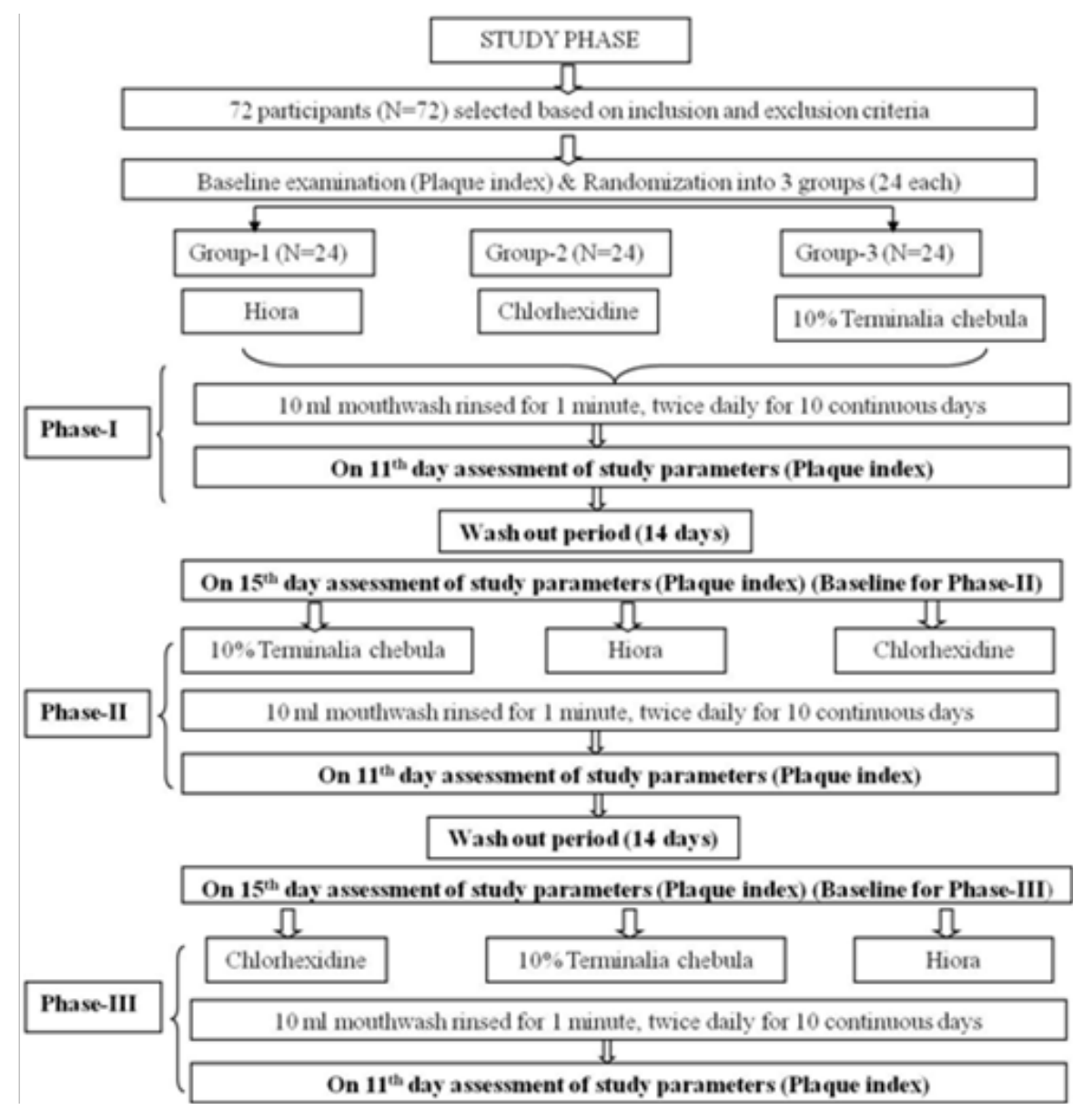

Figure I Different phases of the study. 


\section{Results and discussion}

At the end of the study, all 72 subjects had used all the three study mouthwashes for a period of 10 days each in different phases of present study. In Hiora group, mean plaque index reading in phase I at baseline and after 10 days were observed to be $1.12 \pm 0.34 \& 0.76 \pm 0.25$ respectively with reduction in mean being 0.36 . In phase II, mean plaque index reading at baseline \& after 10 days of use of Hiora mouthwash was observed to be $0.54 \pm 0.20 \& 0.41 \pm 0.18$ respectively with reduction in mean being 0.13 . In phase III, on using Hiora mouthwash, mean plaque index score was observed to be $0.27 \pm 0.05$, whereas the same was observed to be $0.48 \pm 0.09$ at baseline (Tables 1-3). In Chlorhexidine group in phase 1, mean plaque index reading at baseline \& after 10 days of use of Chlorhexidine mouthwash was observed to be $0.50 \pm 0.17 \& 0.24 \pm 0.07$ respectively with reduction in mean being 0.26 . In phase 2 , on using Chlorhexidine mouth wash, mean plaque index score was observed to be $0.57 \pm 0.32$ whereas the same was observed to be $1.23 \pm 0.44$ at baseline. 0.66 was the reduction in mean recorded. Mean plaque index reading at baseline and after 10 days of usage of Chlorhexidine mouthwash in phase III was noted to be $0.76 \pm 0.29 \& 0.44 \pm 0.19$ respectively with reduction in mean being 0.32 (Tables 4-6). In Terminalia chebula group in phase I, mean plaque index reading at baseline \& after 10 days of use of $10 \%$ Terminalia chebula mouthwash was observed to be $0.88 \pm 0.35$ $\& 0.52 \pm 0.20$ respectively with reduction in mean being 0.36 . In phase II, on using $10 \%$ Terminalia chebula mouthwash, mean plaque index score was observed to be $0.30 \pm 0.06$ whereas the same was observed to be $0.49 \pm 0.15$ at baseline. 0.19 was the reduction in mean recorded. Mean plaque index reading at baseline and after 10 days of usage of $10 \%$ Terminalia chebula mouthwash in phase III was noted to be $0.99 \pm 0.46 \& 0.65 \pm 0.35$ respectively with reduction in mean being 0.34 (Tables 7-9).

Table I Comparison of mean PII at baseline \& after 10 days of hiora use in phase I

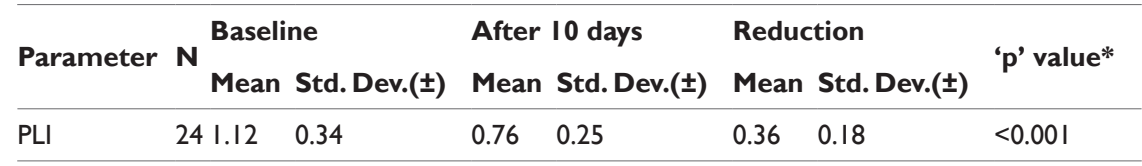

*Paired ' $\mathrm{t}$ ' test, $\mathrm{P}<0.05-$ significant

Table 2 Comparison of mean PII at baseline \& after 10 days of hiora use in phase II

\begin{tabular}{|c|c|c|c|c|c|c|c|}
\hline \multirow{2}{*}{ Parameter } & \multicolumn{2}{|c|}{ Baseline } & \multicolumn{2}{|c|}{ After 10 days } & \multicolumn{2}{|c|}{ Reduction } & \multirow{2}{*}{ 'p' value* } \\
\hline & Mean & Std. Dev.( $( \pm)$ & Mean & Std. Dev.( () & Mean & Std. Dev.( $( \pm)$ & \\
\hline PLI & 240.54 & 0.20 & 0.41 & 0.18 & 0.13 & 0.17 & $<0.001$ \\
\hline
\end{tabular}

*Paired ' $\mathrm{t}$ ' test, $\mathrm{P}<0.05$-significant

Table 3 Comparison of mean PII at baseline \& after 10 days of hiora use in phase III

\begin{tabular}{|c|c|c|c|c|c|c|c|}
\hline \multirow{2}{*}{ Parameter } & \multicolumn{2}{|c|}{ Baseline } & \multicolumn{2}{|c|}{ After 10 days } & \multicolumn{2}{|c|}{ Reduction } & \multirow{2}{*}{ 'p'Value* } \\
\hline & Mean & Std. Dev.( $( \pm)$ & Mean & Std. Dev.( () & Mean & Std. Dev.( $( \pm)$ & \\
\hline PLI & 240.48 & 0.09 & 0.27 & 0.05 & 0.21 & 0.06 & $<0.001$ \\
\hline
\end{tabular}

*Paired ' $\mathrm{t}$ ' test, $\mathrm{P}<0.05-$ significant

Table 4 Comparison of mean pli at baseline \& after 10 days of chlorhexidine use in phase I

\begin{tabular}{|c|c|c|c|c|c|c|c|}
\hline \multirow{2}{*}{ Parameter } & \multicolumn{2}{|c|}{ Baseline } & \multicolumn{2}{|c|}{ After 10 days } & \multicolumn{2}{|c|}{ Reduction } & \multirow{2}{*}{ 'p' value* } \\
\hline & Mean & Std. Dev.( $( \pm)$ & Mean & Std. Dev.( $( \pm)$ & Mean & Std. Dev.( $( \pm)$ & \\
\hline PLI & 240.50 & 0.17 & 0.24 & 0.07 & 0.26 & 0.12 & $<0.001$ \\
\hline
\end{tabular}

*Paired ' $\mathrm{t}$ ' test, $\mathrm{P}<0.05$-significant

Table 5 Comparison of mean pli at baseline \& after 10 days of chlorhexidine use in phase II

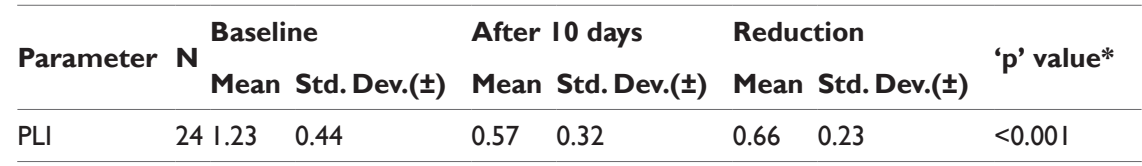

*Paired ' $\mathrm{t}$ ' test, $\mathrm{P}<0.05-$ significant

Table 6 Comparison of mean PII at baseline \& after 10 days of chlorhexidine use in phase III

\begin{tabular}{|c|c|c|c|c|c|c|c|}
\hline \multirow{2}{*}{ Parameter } & \multicolumn{2}{|c|}{ Baseline } & \multicolumn{2}{|c|}{ After 10 days } & \multicolumn{2}{|c|}{ Reduction } & \multirow{2}{*}{ 'p' Value* } \\
\hline & Mean & Std. Dev.( $( \pm)$ & Mean & Std. Dev.( $( \pm)$ & Mean & Std. Dev.( $( \pm)$ & \\
\hline PLI & 240.76 & 0.29 & 0.44 & 0.19 & 0.32 & 0.26 & $<0.001$ \\
\hline
\end{tabular}

*Paired ' $\mathrm{t}$ ' test, $\mathrm{P}<0.05-$ significant 
Table 7 Comparison of mean PII at baseline \& after 10 days of $10 \%$ terminalia chebula use in phase I

\begin{tabular}{|c|c|c|c|c|c|c|c|c|}
\hline \multirow{2}{*}{ Parameter } & \multicolumn{3}{|c|}{ Baseline } & \multicolumn{2}{|c|}{ After 10 days } & \multicolumn{2}{|c|}{ Reduction } & \multirow{2}{*}{ 'p' value* } \\
\hline & & Mean & Std. Dev.( $( \pm)$ & Mean & Std. Dev.( $( \pm)$ & Mean & Std. Dev.( $( \pm)$ & \\
\hline PLI & 24 & 0.88 & 0.35 & 0.52 & 0.20 & 0.36 & 0.25 & $<0.001$ \\
\hline
\end{tabular}

*Paired ' $\mathrm{t}$ ' test, $\mathrm{P}<0.05$ - significant

Table 8 Comparison of mean PII at baseline \& after 10 days of $10 \%$ terminalia chebula use in phase II

\begin{tabular}{|c|c|c|c|c|c|c|c|c|}
\hline \multirow{2}{*}{ Parameter } & \multicolumn{3}{|c|}{ Baseline } & \multicolumn{2}{|c|}{ After 10 days } & \multicolumn{2}{|c|}{ Reduction } & \multirow{2}{*}{ 'p' value* } \\
\hline & & Mean & Std. Dev.( $( \pm)$ & Mean & Std. Dev.( $( \pm)$ & Mean & Std. Dev.( $( \pm)$ & \\
\hline PLI & 24 & 0.49 & 0.15 & 0.30 & 0.06 & 0.19 & 0.16 & $<0.001$ \\
\hline
\end{tabular}

*Paired ' $\mathrm{t}$ ' test, $\mathrm{P}<0.05-$ significant

Table 9 Comparison of mean PII at baseline \& after I0 days of $10 \%$ terminalia chebula use in phase III

\begin{tabular}{|c|c|c|c|c|c|c|c|c|}
\hline \multirow{2}{*}{ Parameter } & \multicolumn{3}{|c|}{ Baseline } & \multicolumn{2}{|c|}{ After 10 days } & \multicolumn{2}{|c|}{ Reduction } & \multirow{2}{*}{ 'p' value* } \\
\hline & & Mean & Std. Dev.( $( \pm)$ & Mean & Std. Dev.( $( \pm)$ & Mean & Std. Dev.( $( \pm)$ & \\
\hline PLI & 24 & 0.99 & 0.46 & 0.65 & 0.35 & 0.34 & 0.22 & $<0.001$ \\
\hline
\end{tabular}

*Paired ' $\mathrm{t}$ ' test, $\mathrm{P}<0.05-$ significant

\section{Discussion}

The results observed regarding plaque reduction after using Hiora mouthwash can be attributed to the presence of Piper betel which in itself has plaque inhibiting property. The findings of present study are in accordance with a study by Anup $\mathrm{N}$ et al., ${ }^{12}$ who also demonstrated the efficacy of Hiora in reducing the plaque. Studies by Narayan A et al. ${ }^{13} \&$ Bhate D et al. ${ }^{14}$ have also reported the efficacy of Hiora as a plaque reducing agent. In contrast to present study, Southern EN et al. ${ }^{15}$ have demonstrated Hiora to be ineffective compared to a placebo in relation to plaque reduction. A study done by Nagesh Bhat et al. ${ }^{16}$ showed that Chlorhexidine was more effective compare to herbal mouthwash. Herbal mouthwash in reducing plaque is quite effective as Chlorhexidine and considered as a good alternative. The Chlorhexidine mouthwash was reported with many side effects which limits its acceptability and long-term use, whereas the presently tested herbal mouthwash had no side effects apart from mild burning sensation. The present study attributed to substantivity property of Chlorhexidine for 12 hours which is considered to be highly effective, whereas the substantivity of herbal mouth rinse is yet to be established. The findings of our study can be correlated with the findings of Bhate D et al. ${ }^{14}$ \& Bagchi et al. ${ }^{17}$ who demonstrated Chlorhexidine to be a highly acceptable antiplaque agent. The findings of our study can be attributed to the presence of Terminalia chebula mouthwash to reduce plaque deposition in addition to its inhibition. ${ }^{18}$ The results of the present study are similar to the studies carried out by Surya Prakash DV et al. ${ }^{19}$ and Nayak SS et al. ${ }^{20}$ who also demonstrated Terminalia chebula to be effective in reducing plaque. Presence of tannin which is present to an extent of $30-40 \%$ may have induced cytotoxic action on the cell membranes of the microorganism. A study done by Gautam Biswas et al. ${ }^{21}$ showed a significant reduction in Plaque scores from baseline to $1^{\text {st }}$ week, $2^{\text {nd }}$ week and at $4^{\text {th }}$ week in both chlorhexidine and herbal mouthwash. But the improvement in plaque index scores were found better in Chlorhexidine group compare to herbal mouthwash group.

\section{Summary \& conclusion}

With the advancement in the field of dentistry, various preventive measures have emerged targeting the causative factors of the oral diseases. Plaque accumulation is one such factor which predisposes an individual to both dental caries and periodontal disease. Based on the overall mean reduction observed in relation to plaque index, Chlorhexidine showed maximum reduction followed by Terminalia chebula, and Hiora. Comparison of overall mean reduction recorded, showed it to be statistically significant between Chlorhexidine and Hiora, and Chlorhexidine and Terminalia Chebula, while the same was statistically not significant between Hiora and Terminalia Chebula. Further studies with varied concentrations, different parameters and larger sample size are to be carried out to assess its efficacy, dosage, and toxicity before they are considered as a meaningful and cost effective addition to mechanical oral hygiene methods.

\section{Acknowledgments}

We are thankful to Orphanage authorities and participants for their kind support.

\section{Conflicts of interest}

The authors declare that there is no conflict of interest.

\section{Funding}

None.

\section{References}

1. Gupta R, Ingle NA, Kaur N, et al. Effectiveness of herbal and nonherbal fluoridated toothpaste on plaque and gingivitis: A randomized controlled trial. 2015;13(3):218-221.

2. Karunakaran R, Somasundaram S, Gawthaman M, et al. Prevalence of dental caries among school-going children in Namakkal district: A crosssectional study. J Pharm Bioallied Sci. 2014;6(Suppl1):S160-S161. 
3. Shaju JP, Zade RM, Das M. Prevalence of periodontitis in the Indian population: A literature review. J Indian Soc Periodontol. 2011;15(1):29-34.

4. Neturi RS, Srinivas R, Vikram Simha B, et al. Effects of Green Tea on Streptococcus mutans Counts-A Randomised Control Trail. J Clin Diagn Res. 2004;8(11):ZC128-ZC130.

5. Gupta D, Nayan S, Tippanawar HK, et al. Are herbal mouthwash efficacious over Chlorhexidine on the dental plaque? Pharmacognosy Res. 2015;7(3):277-281.

6. Sharma R, Hebbal M, Ankola AV, et al. Effect of Two Herbal Mouthwashes on Gingival Health of School Children. J Tradit Complement Med. 2014;4(4):272-278.

7. Halawany HS. A review on miswak (Salvadora persica) and its effect on various aspects of oral health. Saudi Dent J. 2012;24(2):63-69.

8. Bhat N, Mitra R, Reddy JJ, et al. Evaluation of efficacy of Chlorhexidine and A Herbal Mouthwash on Dental Plaque: An In vitro Comparative Study. Int J Pharm Bio Sci. 2013;4(3):625-632.

9. Jagdish L, Anand Kumar VK, Kaviyarasan V. Effect of triphala on dental biofilm. Indian J Sci Technol. 2009;2(1):30-33.

10. Rekha V, Jayamathi, Krishan R, et al. Anti Cariogenic Effect of Terminalia Chebula. J Clin Diagn Res. 2014;8(8):ZC51-ZC54.

11. Loe H. The Gingival Index, the Plaque Index and the Retention Index Systems. J Periodontol. 1967;38(6)Suppl:610-616.

12. Anup N, Acharya V, Shraveni G, et al. Efficacy of Commercially available Herbal mouthrinse on the Plaque and Gingival status among 12-14 yrs old School Children. International Journal of Biological \& Pharmaceutical Research. 2015;6(3):233-235.

13. Narayan A, Mendon C. Comparing the effect of different mouthrinses on de novo plaque formation. J Contemp Dent Pract. 2012;13(4):460-463.
14. Bhate D, Jain S, Kale $\mathrm{R}$, et al.The comparative effects of $0.12 \%$ Chlorhexidine and herbal oral rinse on dental plaque induced gingivitis: A randomized clinical trial. J Indian Soc Periodontol. 2015;19(4):393-395.

15. Southern EN, Combs GBM, Tolle, et al. The Comparative Effects of $0.12 \%$ Chlorhexidine and Herbal Oral Rinse on Dental Plaque-Induced Gingivitis. J Dent Hyg. 2006;80(1):1-10.

16. Bhat N, Mitra R, Oza S, et al. The antiplaque effect of herbal mouthwash in comparison to chlorhexidine in human gingival disease: a randomized placebo controlled clinical trial. J Complement Integr Med. 2014;11(2):129-137.

17. Bagchi S, Saha S, Jagannath GV, et al. Evaluation of efficacy of a commercially available herbal mouthwash on dental plaque and gingivitis: A double blinded parallel randomized controlled trail. Journal of Indian Association of Public Health Dentistry. 2015;13:222-227.

18. Velmurugan A, Madhubala MM, Bhavani S, et al. An in vivo comparative evaluation of two herbal extracts Emblica officinalis and Terminalia Chebula with Chlorhexidine as an anticaries agent: A preliminary study. $J$ Conserv Dent. 2013;16(6):546-549.

19. Surya Prakash DV, Sree Satya N, Avanigadda S, et al. Pharmacological Review on Terminalia Chebula. International Journal of Research in Pharmaceutical and Biomedical Sciences. 2012;3(2):679-683.

20. Sharma N, Charles $\mathrm{CH}$, Lynch $\mathrm{MC}$, et al. Adjunctive benefit of an essential oil containing mouthrinse in reducing plaque and gingivitis in patients who brush and floss regularly A six-month study. J Am Dent Assoc. 2004;135(4):496-504.

21. Biswas G, Anup N, Acharya S, et al. Evaluation of the Efficacy Of $0.2 \%$ Chlorhexidine versus Herbal Oral Rinse on Plaque Induced Gingivitis-A Randomized Clinical Trail. IOSR Journal of Nursing and Health Science. 2014;3(2):58-63. 